\title{
Pengaruh Kepemimpinan Transformasional Dan Motivasi Terhadap Keberhasilan Usaha Di Bekasi
}

\author{
Antonius Stephen dan Mei Ie \\ Program Studi Manajemen Fakultas Ekonomi Universitas Tarumanagara, Jakarta \\ Email: Antoniusstephen23@yahoo.co.id
}

\begin{abstract}
Abstrak: Penelitian ini meneliti variabel kepemimpinan transformasional dan motivasi terhadap keberhasilan usaha UKM di Bekasi. Kepemimpinan transformasional adalah kemampuan seseorang pemimpin dalam bekerja dengan melalui orang lain untuk mentransformasikan. Motivasi adalah suatu dorongan atau alasan yang menjadi dasar semangat seseorang untuk melakukan sesuatu untuk mencapai tujuan tertentu. Keberhasilan usaha adalah suatu keadaan dimana usaha mengalami peningkatan dari hasil yang sebelumnya. Penelitian ini bertujuan untuk menguji secara empiris pengaruh kepemimpinan transformasional dan motivasi terhadap keberhasilan usaha. Sampel pada penelitian ini adalah 50 responden dari berbagai jenis usaha di Bekasi. Pengumpulan data dilakukan dengan melakukan penyebaran kuesioner, dengan menggunakan metode nonprobability sampling. Metode analisis data yang digunakan adalah metode Structural Equation Modeling (SEM) dengan Smart PLS 3. Hasil penelitian menunjukkan bahwa kepemimpinan transformasional berpengaruh positif dengan keberhasilan usaha, serta motivasi juga berpengaruh positif terhadap keberhasilan usaha.
\end{abstract}

Abstract: This study examines transformational leadership variables and motivation for the success of SME businesses in Bekasi. Transformational leadership is the ability of a leader in working with others to transform. Motivation is an encouragement or reason that becomes the basis of one's enthusiasm for doing something to achieve certain goals. Business success is a situation where the business experiences an increase from the previous results. This study aims to empirically examine the effect of transformational leadership and motivation on business success. The sample in this study were 50 respondents from various types of businesses in Bekasi. Data collection is done by distributing questionnaires, using non-probability sampling methods. The data analysis method used is the Structural Equation Modeling (SEM) method with Smart PLS 3. The results showed that transformational leadership has a positive effect on business success, and motivation also has a positive effect on business success.

Keywords: transformasional leadership, motivation, business success.

\section{LATAR BELAKANG}

Sebagai negara dengan potensi pertumbuhan yang besar di Asia, Indonesia termasuk berhasil untuk menurunkan angka kemiskinan akan tetapi menurut Laporan Badan Pusat Statistik menunjukkan rasio gini pada September 2017 sebesar 0,391. Besaran koefisien ini berkurang 0,002 dibandingkan dengan bulan Maret 2017 yang sebesar 0,393. Menteri Koordinator Bidang Perekonomian Darmin Nasution menyatakan bahwa 
walaupun pertumbuhan ekonomi Indonesia yang diproyeksikan naik setiap tahunnya belum mampu diimbangi dengan pemerataan dari sector ekonomi.

Ketimpangan tersebut terjadi akibat terdapat 4 masalah utama, yaitu: yang pertama adalah ketimpangan kesempatan, ketimpangan upah dalam dunia kerja, terjadinya pemusatan kekayaan yang tinggi, guncangan, seperti PHK dan bencana alam. Apabila hal itu terjadi pada keluarga yang tergolong miskin dan rentan miskin, akan mengalami guncangan ekonomi. Di Indonesia, pada saat ini terdapat 11,3 persen atau 28 juta orang yang tergolong miskin. Selain itu, terdapat 26,9 persen atau 68 juta orang yang tergolong rentan miskin yang dapat jatuh miskin akibat guncangan tersebut.(Tirto.id)

Oleh sebab itu, UKM merupakan faktor pendorong utama terciptanya lapangan pekerjaan dan pertumbuhan ekonomi suatu negara. Agar UKM dapat terus bertahan maka UKM tersebut harus mencapai keberhasilan usaha. Keberhasilan usaha merupakan puncak dari suatu proses berwirausaha. Oleh karena itu keberhasilan usaha diteliti sebagai variabel. Agar keberhasilan usaha dapat tercapai, terdapat beberapa variabel yang diteliti, antara lain kepemimpinan transformasional dan motivasi. Kedua variabel tersebut memiliki pengaruh terhadap keberhasilan usaha, terutama UKM. Keberhasilan usaha merupakan suatu ukuran yang menandakan UKM berjalan dengan baik.

Hipotesis dalam penelitian ini adalah terdapat pengaruh positif kepemimpinan transformasional terhadap keberhasilan usaha UKM di Bekasi dan terdapat pengaruh positif motivasi terhadap keberhasilan usaha UKM di Bekasi. Berdasarkan penelitian sebelumnya yang relevan, menurut Gemina terdapat pengaruh motivasi terhadap keberhasilan usaha dan menurut Rinaldi terdapat pengaruh kepemimpinan dan motivasi terhadap keberhasilan usaha. Jadi, permasalahan yang terjadi adalaha banyaknya UKM yang berhenti karena tidak dapat bersaing atau merugi, dengan mengetahui tipe kepemimpinan dan motivasi yang tepat maka dapat memicu usaha UKM untuk terus bertahan. Penelitian ini bertujuan untuk pengusaha UKM dapat berhasil dan menjadi penyokong perekonomian Indonesia.

\section{KAJIAN TEORI}

Menurut Danim (2004:54), kepemimpinan transformasional adalah kemampuan seseorang pemimpin dalam bekerja dengan orang lain dan melalui orang lain guna mempergunakan secara optimal sumber daya organisasi untuk mencapai tujuan yang berguna sesuai dengan target yang telah ditetapkan. Menurut Sardiman (2006:73) motivasi merupakan suatu perubahan energi dalam pribadi seseorang yang ditandai dengan munculnya perasaaan dan didahului dengan tanggapan terhadap adanya sebuah tujuan. Menurut Hendry (2007:397) mengungkapkan bahwa keberhasilan usaha pada hakikatnya adalah keberhasilan dalam bisnis karena dianggap telah mencapai tujuanya.

Berdasarkan penelitian yang sudah ada sebelumnya, terdapat pengaruh kepemimpinan transformasional dan motivasi terhadap keberhasilan usaha khususnya Usaha Kecil dan Menengah (UKM), berikut penjelasannya.

Berdasarkan penelitian yang dibuat oleh Gemina dkk. (2016) penelitian ini bertujuan untuk melihat pengaruh motivasi usaha terhadap keberhasilan usaha dengan kemampuan usaha sebagai variabel mediasi pada industry kecil menengah makanan ringan Priangan Timur-Indonesia. Sampel yang dipergunakan oleh peneliti sebanyak 150 sampel yang terbagi 3 daerah setiap 50 sampel, yaitu kota Tasikmalaya, kota Bandung dan kota 
Garut. Analisis data yang dipergunakan oleh peneliti adalah path analysis. Hasil penelitian menunjukkan bahwa motivasi secara parsial berpengaruh positif terhadap keberhasilan usaha.

Berdasarkan penelitian yang dibuat oleh Rinaldi (2017) penelitian ini bertujuan untuk melihat pengaruh kepemimpinan dan motivasi berwirausaha terhadap keberhasilan usaha pada jajanan malam MMTC jalan Pancing, Medan. Sampel yang dipergunakan oleh peneliti adalah sebanyak 40 pedagang. Analisis data yang dipergunakan oleh peneliti adalah analisis deskriptif. Hasil penelitian menunjukkan bahwa kepemimpinan dan motivasi secara parsial berpengaruh positif terhadap keberhasilan usaha.

Berdasarkan penelitian yang dibuat oleh Herdiana (2017) penelitian ini bertujuan untuk mengetahui pengaruh gaya kepemimpinan wirausaha, motivasi dan lingkungan terhadap produktivitas usaha bordir di kecamatan Kawalu kota Tasikmalaya. Sampel yang diperunakan sebanyak 51 orang dan analisis yang dipergunakan adalah analisis path. Hasil penelitian menunjukkan bahwa gaya kempemimpinan wirausaha, motivasi dan lingkungan berpengaruh terhadap produktivitas usaha.

Berdasarkan penelitian yang dibuat oleh Daulay, Rina \& Ramadini, Frida (2013) penelitian ini bertujuan untuk mengetahui pengaruh efikasi diri dan motivasi terhadap keberhasilan usaha fotocopy dan alat tulis kantor di kecamatan Panyabungan kabupaten Mandailing Natal. Sampel yang dipergunakan sebanyak 50 toko dan analisis data yang dipergunakan adalah analisis deskriptif. Hasil penelitian menunjukkan bahwa efikasi diri dan motivasi berpengaruh terhadap keberhasilan usaha.

Berdasarkan penelitian yang dibuat oleh Purnama (2010) penelitian ini bertujuan untuk mengetahui pengaruh motivasi dan kemampuan usaha dalam meningkatkan keberhasilan usaha industry kecil (studi pada industri kecil sepatu di Jawa Timur). Sampel yang dipergunakan pada penelitian ini sebanyak 100 pengusaha industry sepatu. Analisis data yang dipergunakan adalah stratified cluster sampling. Hasil pada penelitian ini menunjukkan adanya pengaruh motivasi dan kemampuan usaha dalam meningkatkan keberhasilan usaha industri kecil sepatu di Jawa Timur.

\section{METODOLOGI}

Jenis penelitian ini merupakan penelitian kuantitatif. Penelitian kuantitatif adalah jenis pengukuran data yang datanya memiliki sifat statistik melalui perhitungan ilmiah dari para responden yang diminta guna mengisi kuisioner yang diberikan untuk dapat menetapkan proporsi presentase tanggapan para responden. Populasi dalam penelitian ini adalah pengusaha UKM di Bekasi.

Penelitian ini menggunakan data yang diperoleh dari para pelaku UKM di kota Bekasi. Penelitian ini menggunakan penelitian konklusif dengan mengambil penelitian deskriptif sebagai konsentrasinya. Teknik yang akan dipergunakan dalam penelitian deskriptif ini adalah cross-sectional, yaitu variabel dari penelitian ini hanya diukur sekali. Penelitian ini menggunakan sampel sebesar 50 UKM. 


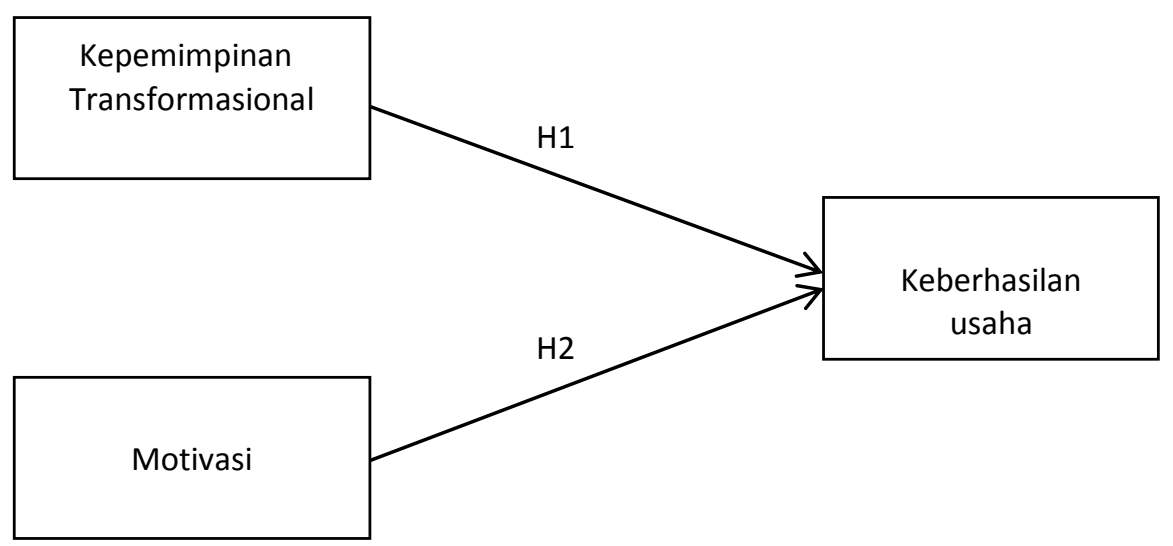

Kerangka Pemikiran

\section{Hasil Analisis Data}

1. Loading Factor

Output Loading Factor Variabel Kepemimpinan Transformasional

\begin{tabular}{|c|c|c|}
\hline Variabel & Indikator & Nilai Loading Factor \\
\hline \multirow{8}{*}{$\begin{array}{l}\text { Kepemimpinan } \\
\text { Transformasional }\end{array}$} & \multirow[b]{2}{*}{ K1 } & 0.8856 \\
\hline & & 0.8956 \\
\hline & \multirow[b]{2}{*}{ K2 } & 0.8703 \\
\hline & & 0.8468 \\
\hline & \multirow[b]{2}{*}{ K3 } & 0.8857 \\
\hline & & 0.9155 \\
\hline & \multirow[b]{2}{*}{ K4 } & 0.8979 \\
\hline & & 0.6463 \\
\hline
\end{tabular}

Sumber : Hasil Pengolahan Data

Output Loading Factor Variabel Motivasi

\begin{tabular}{|l|l|l|}
\hline Variabel & Indikator & Nilai Loading Factor \\
\hline \multirow{2}{*}{ Motivasi } & \multirow{2}{*}{ M1 } & 0.8390 \\
\cline { 3 - 3 } & & 0.9046 \\
\cline { 3 - 3 } & & 0.8889 \\
\cline { 3 - 3 } & & 0.8267 \\
\cline { 2 - 3 } & & 0.8727 \\
\cline { 3 - 3 } & & 0.8696 \\
\hline
\end{tabular}


Stephen dan Ie: Pengaruh Kepemimpinan Transformasional...

\begin{tabular}{|c|c|c|}
\hline & \multirow[t]{2}{*}{$\mathrm{M} 2$} & 0.8803 \\
\hline & & 0.7866 \\
\hline \multicolumn{3}{|c|}{ Sumber : Hasil Pengolahan Data } \\
\hline \multicolumn{3}{|c|}{ Output Loading Factor Variabel Keberhasilan Usaha } \\
\hline Variabel & Indikator & Nilai Loading Factor \\
\hline \multirow{5}{*}{ Keberhasilan Usaha } & $\mathrm{Y} 1$ & 0.8875 \\
\hline & $\mathrm{Y} 2$ & 0.9017 \\
\hline & Y3 & 0.9229 \\
\hline & Y4 & 0.8620 \\
\hline & Y5 & 0.9224 \\
\hline
\end{tabular}

Sumber : Hasil Pengolahan Data

2. Cross Loading

Tabel Cross Loading

\begin{tabular}{|c|c|c|c|}
\hline & $\begin{array}{l}\text { Kepemimpinan } \\
\text { Transformasional }\end{array}$ & Motivasi & Keberhasilan Usaha \\
\hline \multirow[b]{2}{*}{$\mathrm{K} 1$} & 0.886 & 0.854 & 0.857 \\
\hline & 0.896 & 0.819 & 0.863 \\
\hline \multirow[b]{2}{*}{ K2 } & 0.870 & 0.855 & 0.822 \\
\hline & 0.847 & 0.812 & 0.808 \\
\hline \multirow[b]{2}{*}{ K3 } & 0.886 & 0.832 & 0.870 \\
\hline & 0.916 & 0.873 & 0.891 \\
\hline \multirow[b]{2}{*}{ K4 } & 0.898 & 0.861 & 0.799 \\
\hline & 0.646 & 0.617 & 0.531 \\
\hline \multirow{4}{*}{ M1 } & 0.817 & 0.839 & 0.762 \\
\hline & 0.878 & 0.905 & 0.854 \\
\hline & 0.846 & 0.889 & 0.820 \\
\hline & 0.807 & 0.827 & 0.737 \\
\hline \multirow{4}{*}{ M2 } & 0.840 & 0.873 & 0.840 \\
\hline & 0.827 & 0.870 & 0.855 \\
\hline & 0.858 & 0.880 & 0.879 \\
\hline & 0.781 & 0.787 & 0.768 \\
\hline Y1 & 0.837 & 0.819 & 0.888 \\
\hline
\end{tabular}


Stephen dan Ie: Pengaruh Kepemimpinan Transformasional...

\begin{tabular}{|l|l|l|l|}
\hline Y2 & 0.881 & 0.878 & 0.902 \\
\hline Y3 & 0.877 & 0.879 & 0.923 \\
\hline Y4 & 0.810 & 0.829 & 0.862 \\
\hline Y5 & 0.849 & 0.873 & 0.922 \\
\hline
\end{tabular}

Sumber : Hasil Pengolahan Data

3. Fornell-Larcker Criterion

Output Fornell-Larcker Criterion

\begin{tabular}{|c|c|c|c|}
\hline & Keberhasilan Usaha & $\begin{array}{c}\text { Kepemimpinan } \\
\text { Transformasional }\end{array}$ & Motivasi \\
\hline Keberhasilan Usaha & 1.000000 & & \\
\hline $\begin{array}{c}\text { Kepemimpinan } \\
\text { Transformasional }\end{array}$ & 0.946120 & 1.000000 & \\
\hline Motivasi & 0.950091 & 0.968428 & 1.000000 \\
\hline
\end{tabular}

Sumber : Hasil Pengolahan Data

4. Average Variances Extracted (AVE)

Average Variances Extracted (AVE)

\begin{tabular}{|c|c|}
\hline Variabel & Average Variances Extracted \\
\hline Kepemimpinan Transformasional & 0.738 \\
\hline Motivasi & 0.738 \\
\hline Keberhasilan Usaha & 0.809 \\
\hline
\end{tabular}

Sumber : Hasil Pengolahan Data

5. Composite Reliability

Output Composite Reliability

\begin{tabular}{|c|c|c|c|}
\hline Variabel & Acceptance & Composite Reliability & Reliability \\
\hline $\begin{array}{c}\text { Keberhasilan } \\
\text { Usaha }\end{array}$ & $>0.8$ & 0.955 & Reliabel \\
\hline $\begin{array}{c}\text { Kepemimpinan } \\
\text { Transformasional }\end{array}$ & $>0.8$ & & Reliabel \\
\hline Motivasi & $>0.8$ & 0.957 & Reliabel \\
\hline
\end{tabular}


Sumber : Hasil Pengolahan Data

6. Uji Multikolinearitas

Output Collinearity Statistics (VIF)

\begin{tabular}{|c|c|}
\hline Variabel & Nilai VIF \\
\hline \multirow[b]{2}{*}{ K1 } & 3.174 \\
\hline & 4.499 \\
\hline \multirow[b]{2}{*}{$\mathrm{K} 2$} & 4.799 \\
\hline & 3.254 \\
\hline \multirow[b]{2}{*}{ K3 } & 3.877 \\
\hline & 5.199 \\
\hline \multirow[b]{2}{*}{ K4 } & 5.052 \\
\hline & 2.093 \\
\hline \multirow{4}{*}{ M1 } & 3.520 \\
\hline & 4.741 \\
\hline & 4.120 \\
\hline & 3.848 \\
\hline \multirow{4}{*}{ M2 } & 4.470 \\
\hline & 3.387 \\
\hline & 3.664 \\
\hline & 2.362 \\
\hline Y1 & 3.564 \\
\hline Y2 & 3.573 \\
\hline Y3 & 4.752 \\
\hline Y4 & 3.062 \\
\hline Y5 & 4.662 \\
\hline
\end{tabular}

Sumber : Hasil Pengolahan Data

7. Uji Path Coefficient

Output Path Coefficient

\begin{tabular}{|l|c|c|c|}
\hline & $\begin{array}{c}\text { Keberhasilan } \\
\text { Usaha }\end{array}$ & $\begin{array}{c}\text { Kepemimpinan } \\
\text { Transformasional }\end{array}$ & Motivasi \\
& & \\
\hline
\end{tabular}


Stephen dan Ie: Pengaruh Kepemimpinan Transformasional...

\begin{tabular}{|c|c|c|c|}
\hline \hline Keberhasilan & & & \\
Usaha & & & \\
\hline Kepemimpinan & 0.419 & & \\
Transformasional & & & \\
\hline Motivasi & 0.545 & & \\
\hline
\end{tabular}

Sumber : Hasil Pengolahan Data

8. Structural Model (Inner Model)

R-squared coefficients

\begin{tabular}{|l|c|}
\hline \multicolumn{1}{|c|}{ Variabel } & $\boldsymbol{R}$-Square \\
\hline Keberhasilan Usaha & 0.914 \\
\hline
\end{tabular}

Sumber : Hasil Pengolahan Data

$Q^{2}=1-\left(1-0,914^{2}\right)$

$Q^{2}=0.835$

9. Hasil Bootstrapping 


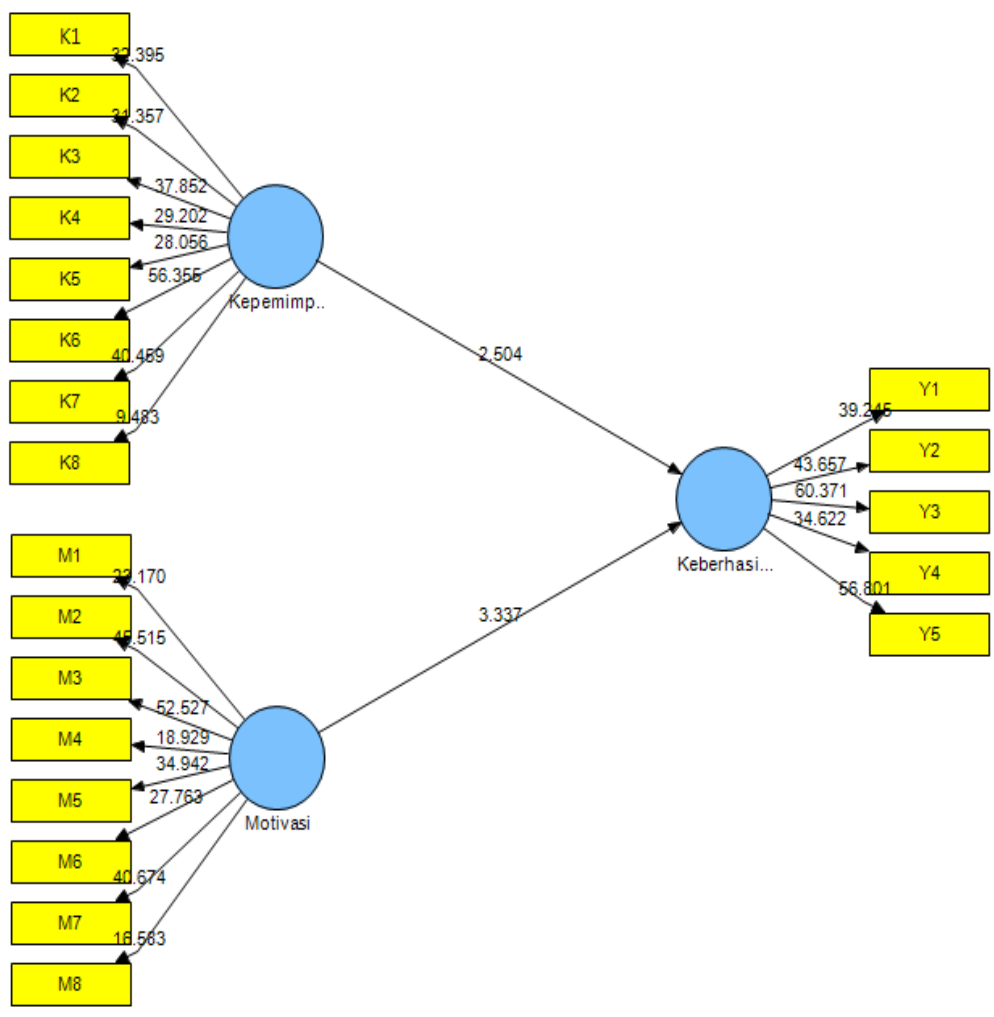

Diagram Path

Sumber : Hasil Pengolahan Data PLS (Lampiran 11)

10. Analisis Pengaruh Langsung

\section{Pengaruh Langsung}

\begin{tabular}{|l|c|c|c|c|c|}
\hline & $\begin{array}{c}\text { Original } \\
\text { Sample } \\
\text { (O) }\end{array}$ & $\begin{array}{c}\text { Sample } \\
\text { Mean } \\
\text { (M) }\end{array}$ & $\begin{array}{c}\text { Standard } \\
\text { Deviation } \\
\text { (STDEV) }\end{array}$ & $\begin{array}{c}\text { Standard } \\
\text { Error } \\
\text { (STERR) }\end{array}$ & $\begin{array}{c}\text { T Statistics } \\
\text { (O/STERR) }\end{array}$ \\
\hline $\begin{array}{l}\text { Kepemimpinan } \\
\text { Transfromasional -> }\end{array}$ & & & & & \\
Keberhasilan Usaha & 0.418 & 0.412 & 0.167 & 0.167 & 2.504 \\
\hline Motivasi -> & & & & & \\
Keberhasilan Usaha & 0.544 & 0.551 & 0.163 & 0.163 & 3.337 \\
\hline
\end{tabular}

Sumber : Hasil Pengolahan Data 


\section{DISKUSI}

Berdasarkan kepada hipotesis pertama dan kedua, bahwa kepemimpinan transformasional dan motivasi terhadap keberhasilan usaha, hasil penelitian menunjukkan bahwa adanya hubungan yang terkait. Penelitian ini dibuat sebagai dasar pengetahuan kepada para pemilik UKM di Indonesia agar para pengusaha UKM dapat meraih keberhasilan usaha dalam bisnisnya dan membantu perekonomian Indonesia.

\section{PENUTUP}

Berdasarkan kepada penelitian yang telah dilakukan, kepemimpinan transformasional yang meliputi pengaruh idealis, motivasi yang menginspirasi, stimulasi intelektual dan pertimbangan individual serta motivasi yang meliputi motivasi internal dan eksternal, perlu dipelajari oleh para UKM untuk dapat meraih keberhasilan usaha.

\section{DAFTAR PUSTAKA}

Arham, A.F., Boucher, C., \& Muenjohn, N. (2013). Leadership and entrepreneurial success : a study of SMEs. World Journal of Social Sciences, vol 3, 117-130.

Chu, H. M., Orhan Kara, Xiaowei Zhu, Kubilay Gok. (2011). Chinese entrepreneurs : motivation, success factors, problem and business related stress. Journal of Chinese Entrepreneurship, vol 3, 84-111.

Danim, Sudarwan. (2004). Motivasi kepemimpinan dan efektivitas kelompok. Jakarta: Rineka Cipta Utama.

Dulay, R. \& Ramadini, F. (2013). Pengaruh efikasi diri dan motivasi terhadap keberhasilan usaha pada usaha fotocopy dan alat tulis kantor di Kecamatan Panyabungan Kabupaten Mandailing Natal. Jurnal Universitas Sumatera Utara, vol 1, 1-8.

Gemina, D., Silaningsih, E., \& Yuningsih, E. (2016). Pengaruh motivasi usaha terhadap keberhasilan usaha dengan kemampuan usaha sebagai variabel mediasi pada industry kecil menengah makanan ringan Priangan Timur-Indonesia. Jurnal Manajemen Teknologi, vol 3, 297-323.

Hendry.F.N. (2007). Ekonomi manajerial. Jakarta: PT Raja Grafindo Persada.

Herdiana, H \& Masitoh, N. (2017). Pengaruh gaya kepemimpinan wirausaha, motivasi dan lingkungan terhadap produktivitas usaha bordir di kecamatan Kawalu, Tasikmalaya. Universitas Siliwangi. Tasikmalaya.

file:///C:/Users/Acer\%20V5/Downloads/332-703-1-SM\%20(4).pdf

Odumeru, James.A., \& Ogbonna, I.G. (2013). Transformational vs Transactional leadership theories: evidence in literature. International Riview Of Management and Business Research, vol 2, 335-361.

Rinaldi, E.J. (2017).Pengaruh kepemimpinan dan motivasi berwirausaha terhadap keberhasilan usaha pada jajanan malam MMTC. Universitas Sumatera Utara. Medan.

(http://repositori.usu.ac.id/handle/123456789/1046)

Sardiman, A.M. (2006). Interaksi dan motivasi belajar-mengajar. Jakarta: PT Raja Grafindo Persada.

https://tirto.id/lingkaran-setan-ketimpangan-sosial-di-indonesia-cFhB 